Article

\title{
A Three-Level Universal Electric Vehicle Charger Based on Voltage-Oriented Control and Pulse-Width Modulation
}

\author{
Ali Saadon Al-Ogaili ${ }^{1, *}$, Ishak Bin Aris ${ }^{2} @$, Renuga Verayiah ${ }^{3}$, Agileswari Ramasamy ${ }^{4}$, \\ Marayati Marsadek ${ }^{1}$, Nur Azzammudin Rahmat ${ }^{3}$, Yap Hoon $\left.{ }^{5}{ }^{(}\right)$, Ahmed Aljanad ${ }^{1}$ and \\ Ahmed N. Al-Masri ${ }^{6}(\mathbb{D}$ \\ 1 Institute of Power Engineering (IPE), Universiti Tenaga National, Kajang 43000, Selangor, Malaysia; \\ Marayati@uniten.edu.my (M.M.); amj422@gmail.com (A.A.) \\ 2 Department of Electrical and Electronic Engineering, Faculty of Engineering, Universiti Putra Malaysia, \\ Serdang 43400, Selangor, Malaysia; ishak_ar@upm.edu.my \\ 3 Department of Electrical Power Engineering, Universiti Tenaga National, Kajang 43000, Selangor, Malaysia; \\ Renuga@uniten.edu.my (R.V.); Azzammudin@uniten.edu.my (N.A.R.) \\ 4 Department of Electronic and Communication Engineering, Universiti Tenaga National, Kajang 43000, \\ Selangor, Malaysia; Agileswari@uniten.edu.my \\ 5 School of Engineering, Faculty of Innovation and Technology, Taylor's University, Subang Jaya 47500, \\ Selangor, Malaysia; Yap.Hoon@taylors.edu.my \\ 6 College of Education, American University in the Emirates, Dubai, Academic City, Dubai 503000, \\ United Arab Emirates; ahmed.almasri@aue.ae \\ * Correspondence: alinasrieh.edu@gmail.com; Tel.: +60-17-3595-053
}

Received: 11 March 2019; Accepted: 13 May 2019; Published: 20 June 2019

check for updates

\begin{abstract}
Electric vehicles (EVs) could be used to address the issues of environmental pollution and the depletion of non-renewable energy resources. EVs, which are energized by a battery storage system, are becoming attractive because they keep the environment clean. Furthermore, the cost of EVs is becoming cheaper. Thus, EVs will become a significant load on utility distribution system in the future. EV chargers play a significant role in the expansion of EVs. The input current of an EV charger with a high total harmonic distortion (THD) and a high ripple distortion of the output voltage can impact battery life and battery charging time. Furthermore, the high cost and large size of the chargers are considered other issues in EV development. This work presents the complete design process of a universal EV charger with a special focus on its control algorithms. In this regard, a novel control algorithm based on the integration of voltage-oriented control (VOC) and the sinusoidal pulse-width modulation (SPWM) technique is proposed to ensure effective Levels 1, 2, and 3 battery charging. A simulation of the universal EV charger was conducted and assessed in MATLAB-Simulink. Moreover, a laboratory prototype was constructed with a TMS320F28335 digital signal processor (DSP) programmed as the controller to validate its operation and performance. The findings show that the proposed charger is able to provide a controllable and constant charging voltage for a variety of EVs, with an input current of low total harmonic distortion (THD) and an almost unity power factor.
\end{abstract}

Keywords: decoupled controller; electric vehicle; sinusoidal PWM; three-level charging; voltage-oriented control (VOC); total harmonic distortion (THD)

\section{Introduction}

Nowadays, most of the vehicles in the transportation system are still dependent on liquid fossil fuels, which are slowly being depleted. Fifty percent of crude oil production is used by vehicles 
in the transportation sector. The continuous consumption of liquid fossil fuels has led to increased atmospheric absorptions of greenhouse gases (GHG), especially carbon dioxide. For such reasons, shifting the global energy demand away from fossil fuels towards sustainable transportation is becoming a critical matter. In this context, full electric or hybrid road vehicles have attracted attention as good solutions to the above problems of liquid fossil fuel dependency [1].

Electric vehicles (EVs) have become an important factor in the growth of automobile manufacturing. EVs are operated by an electric motor that receives power from a rechargeable battery. Presently, there are two charging techniques for EVs, namely AC and DC charging [2-5]. For AC charging, single-phase or three-phase AC power is supplied to an on-board AC-DC power converter in the EV. Meanwhile, DC charging is performed by directly supplying DC power to the battery of the EV via an off-board AC-DC power converter. The use of on-board chargers will definitely increase the charging accessibility of the vehicle; meanwhile, off-board chargers allow the use of higher rating circuits. Thus, the off-board charger completes the charging in a shorter period of time. An off-board charger is actually available as an external unit, rather than being a part of the EV. A typical off-board charger is able to produce a higher DC voltage. For practical purposes, a battery management system (BMS) is required to operate the battery system safely and efficiently for an extended life. The BMS is used is to provide a reliable estimate of the crucial internal states such as the state of charge (SOC) and the instantaneous capacity, which is an indicator of the State of Health (SOH) [6]. As a result, the BMS should have the ability to charge the battery by using this voltage. Nevertheless, the main weakness of this type of design is that the charger is not installed as a part of the EV. Therefore, the charging of the EV battery can only be done with a specific charger that is capable of providing the required amount of DC voltage. In contrast to an off-board charger, an on-board charger is a part of the EV, which allows for charging at almost any location possible as long as single-phase or three-phase supply is available.

Owing to the advancements in EV technologies, the design of a reliable, efficient, and high power density charger has become a great challenge. One of the common issues with EV charging is the use of power electronics converters that potentially create harmonics issues in the grid. These harmonics have impacts on the power quality (PQ) of the low-voltage (LV) distribution network. They can negatively affect the stability as well $[7,8]$. Furthermore, the input current of an EV charger with high total harmonic distortion (THD) can subsequently cause many problems for the other electronic devices that are used in the charger station. As the level of harmonics increases within the supply, there can be unwanted side effects in the charging stations, such as conductor and transformer heating. In addition, the harmonic current levels can cause voltage distortion in the supply, which may also cause unwanted effects for other electrical equipment connected to the same mains supply. Moreover, the chargers also suffer from high ripples of DC-link voltage which can damage the battery. The existing battery chargers are designed to charge only one level of the charging mode. Therefore, there is a lack of flexibility in terms of providing multi-modes charging. Level 1 charging can draw $1.4-1.9 \mathrm{~kW}$ of power based on the ampere rating, while the time required to fully charge the battery of an EV is 6-8 $\mathrm{h}$ [9]. The required power of Level 2 charging is $7.7-25.6 \mathrm{~kW}$, and it commonly takes $4-8 \mathrm{~h}$ to fully charge [10]. The output power of Level 3 charging is $50-100 \mathrm{~kW}$, and it requires $1-3 \mathrm{~h}$ to fully charge the battery of a heavy-duty-vehicle [11,12].

Various control algorithms have been developed to charge EVs. These control algorithms have been introduced to limit the harmonic content of the current drawn from the power line by the rectifiers, such as direct power control (DPC) [13], but this type of controller needs high inductance and sample frequency. In [14], hysteresis control, originally used for thermostatically controlled loads [15], is employed for plug-in electric vehicle (PEV) charging to actively control the aggregated consumption of a higher number of chargers. However, variable switching frequency and the possibilities of limit cycle operation with high-frequency switching are the disadvantages of this type of controller.

In addition, numerous studies have established that model predictive control (MPC) yields a smaller total harmonic distortion (THD) and a smaller mean absolute current reference tracking error as compared to other controllers. For example, in [16], the authors presented a predictive current control 
method to minimize the THD by using a switching frequency of $8 \mathrm{kHz}$ with a voltage source inverter. In [17], the researchers implemented a four-leg converter by applying a model predictive current control algorithm, where the THD and switching frequency were observed at low values of the filter parameter. A comparative study between a finite-control-set MPC (FCS-MPC) and synchronous proportional integral (PI) controller with space vector modulation (PI-SVP) was presented in [18]; it was observed that the FCS-MPC is able to generate waveforms with fewer low-order harmonics than the PI-SVM. The MPC method is able to operate with different voltage/frequency values while maintaining a lower THD value [19-21]. However, MPC requires complex implementation as compared to linear controllers. Meanwhile, in the single-phase on-board bidirectional charger proposed by [22], PI controllers were employed in AC/DC converters and DC/DC converters to provide constant voltage and constant current charging, as well as reactive power compensation. However, the total THD of the line current was high. In [23], the authors proposed a unidirectional EV charger managed by direct power control. The charger was sufficient in providing a utility with reactive power support and other vehicle-to-grid benefits, but the work did not study the grid-to-vehicle (G2V) impact.

This work presents the novel design and development of a universal EV charger. This EV charger is capable of three levels of EV charging, providing single-phase AC, three-phase AC, and DC charging, as shown in Figure 1. Hence, it is suitable for all three levels of charging. As such, this work focuses on scenarios where there are limitations in terms of space and resources available. In this regard, a more compact universal charging strategy will be advantageous. Specifically, in this work, the voltage-oriented control (VOC) technique is proposed to control the three-stage converters of the EV charger. These stages are a pulse-width modulation (PWM) rectifier, sinusoidal pulse-width modulation (SPWM) inverters, and a diode bridge rectifier. The proposed VOC technique demonstrates highly dynamic operation, appropriate output voltage, and a low THD of the input current.

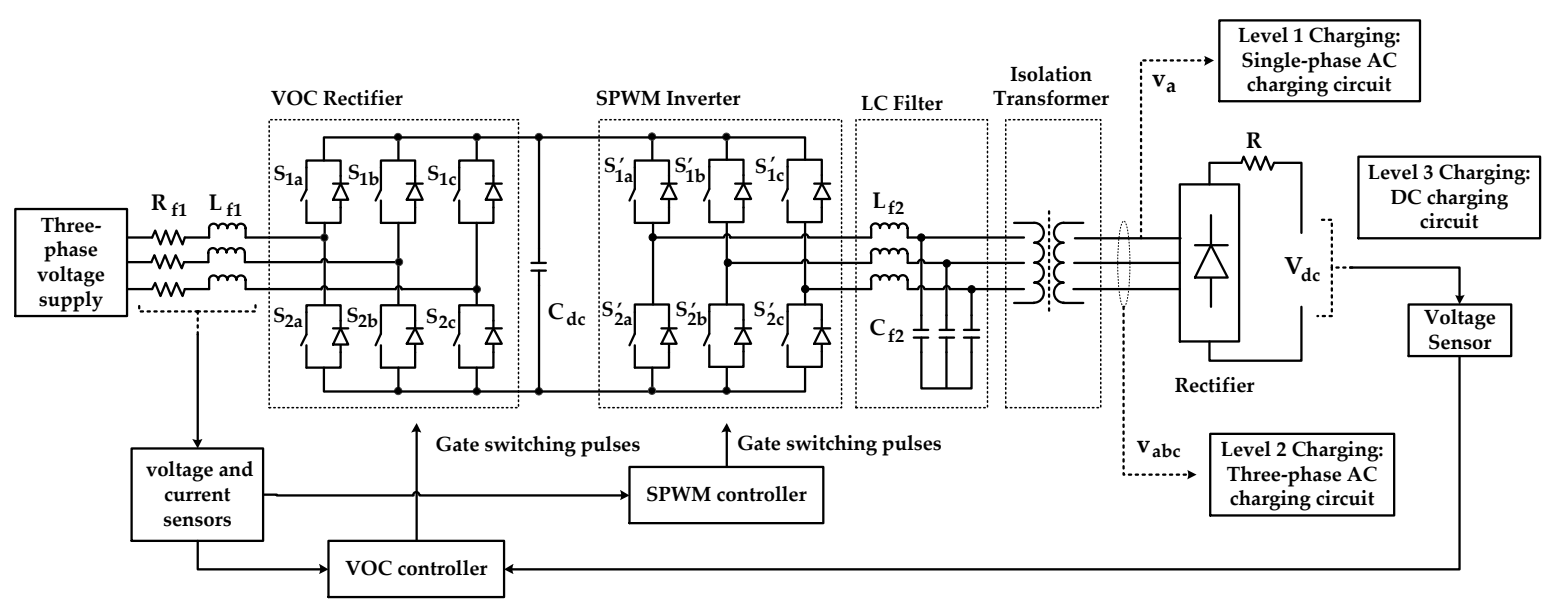

Figure 1. The proposed electric vehicle (EV) universal charger of three-stage converters based on the voltage-oriented control (VOC) algorithm.

In addition, the components of an EV universal charger and the control strategies involved, are presented. As seen in Figure 1, the sensing circuits are located at the initial stage of control (VOC rectifier), where they provide the status of all related system variables to the control algorithms. Subsequently, the measured variables are processed by the control algorithms and are compared with their respective reference values to generate gating PWM pulses for controlling the switching operation of the converters.

The proposed charging method is implemented in a compact manner that reduces the overall size and weight. More importantly, the proposed method is designed to be universal, as it can provide all three levels of charging; single-phase AC, three-phase AC, and DC charging. In other words, the proposed method is more versatile and advantageous in certain scenarios, especially when there are limitations in terms of space and resources. Thus, in charging stations, a universal charger can save 
space and equipment costs (such as acquisition and maintenance costs) while being able to provide both AC and DC charging protocols to EVs.

The key contributions of this paper are as follows:

(1) A charger system composed of three levels of charging: Single-phase 120 V/16 A AC for a motorcycle (Level 1), three-phase 240 V/60 AC for a saloon car (Level 2), 650 V/100 A DC for a bus or lorry (Level 3), and battery charging.

(2) The proposed universal charger system is controlled digitally and implemented on a TMS320F28335 digital signal processor (DSP) board.

(3) The charger system is designed with three stages of converters: A PWM VOC rectifier, SPWM inverters, and a diode bridge rectifier. These provide the results of a unity power factor at the input stage, and the total harmonic distortion (THD) of the input current is approximately $0.83 \%$.

(4) The charger system satisfies the voltage control and the isolation between the grid and vehicle through a three-phase transformer integrated with the charger system. The secondary output of the transformer is able to provide Levels 1 and 2 of charging, while the whole circuit output can provide Level 3 DC charging.

The remainder of this paper is organized as follows. Section 2 presents a general review of the VOC model. Section 3 briefly describes the three-stage converters and the modeling of the EV charger. Section 4 describes the simulation setup of the work using the MATLAB/Simulink 2010a software and the experimental setup in a laboratory to verify the performance of the proposed algorithm. Sections 5 and 6 present the simulation and experimental findings, respectively. A benchmarking analysis is provided in Section 7. The final section concludes and highlights the important contributions of this work.

\section{Voltage-Oriented Control}

Field-oriented control (FOC) for induction motors is the origin of the voltage-oriented control method for AC-DC converters. FOC provides a fast, dynamic response because of the use of loops of current control. The VOC technique applied for grid-connected rectifiers has been widely reported in its theoretical aspects. The PWM method is associated with the control system, which is applied to ensure that the features of the VOC control system are varied. The effect of interference (disturbances) can be minimized. System solidity is accomplished by applying the hysteresis pulse-width modulation technique. The changing switching frequency contributes to stress in power switching, which results in the need for an input filter at high-value parameters.

To minimize the harmonics issues, the proposed method applies the VOC principle to control the charging process while maintaining low harmonic distortions to the grid. Figure 2 shows the voltage-oriented control for AC-DC line-side converters. The operation of VOC is mainly performed in the two-phase $\alpha \beta 0$ and $d q 0$ domains, where Clarke and Park transformation matrices, as shown in Equations (1) and (2), respectively, are applied:

$$
\begin{gathered}
{\left[\begin{array}{c}
v_{S \alpha} \\
v_{S \beta} \\
v_{0}
\end{array}\right]=\sqrt{\frac{2}{3}}\left[\begin{array}{ccc}
1 & \frac{-1}{2} & \frac{-1}{2} \\
0 & \frac{\sqrt{3}}{2} & -\frac{\sqrt{3}}{2} \\
\frac{1}{\sqrt{2}} & \frac{1}{\sqrt{2}} & \frac{1}{\sqrt{2}}
\end{array}\right]\left[\begin{array}{c}
v_{S a} \\
v_{S b} \\
v_{S c}
\end{array}\right]} \\
{\left[\begin{array}{c}
v_{d} \\
v_{q}
\end{array}\right]=\left[\begin{array}{cc}
\sin \theta & \cos \theta \\
-\cos \theta & \sin \theta
\end{array}\right]\left[\begin{array}{c}
v_{S \alpha} \\
v_{S \beta}
\end{array}\right]}
\end{gathered}
$$

Note that $v_{S a}, v_{S b}$ and $v_{S_{c}}$ are the three-phase source voltages in $a b c$ domain, $v_{S \alpha}, v_{S \beta}, v_{d}, v_{q}$ and $v_{0}$ are the source voltages in the $\alpha \beta 0$ and $d q 0$ domains, and $\theta$ is the operating phase of the power system. A similar transformation process is applied to convert the three-phase source current $i_{S a b c}$, as illustrated in Figure 2. 


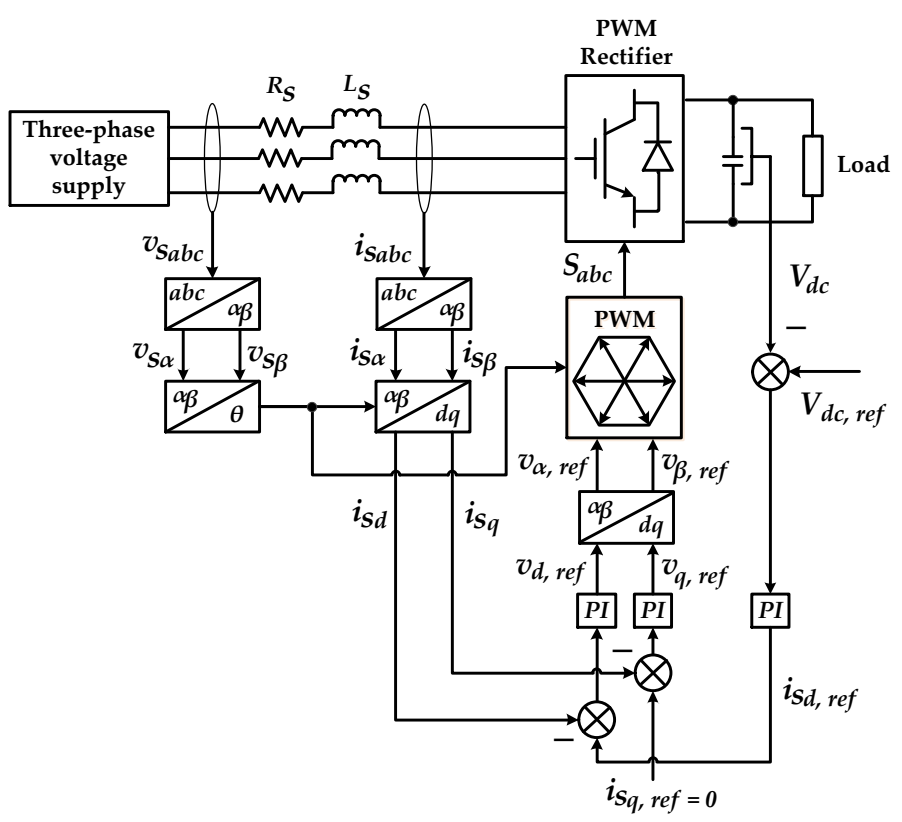

Figure 2. Overall control structure of voltage-oriented control of a pulse-width modulation (PWM) rectifier [24].

By using the transformation technique, AC side control variables will become DC signals; in this manner, steady-state errors are easily eliminated by the proportional integral (PI) controllers according to the following approaches:

$$
\begin{aligned}
& v_{d, r e f}=K_{p}\left(i_{S d, r e f}-i_{S d}\right)+K_{i} \int\left(i_{S d, r e f}-i_{S d}\right) d t \\
& v_{q, \text { ref }}=K_{p}\left(i_{S q, r e f}-i_{S q}\right)+K_{i} \int\left(i_{S q, r e f}-i_{S q}\right) d t
\end{aligned}
$$

where $K_{p}$ and $K_{i}$ are the gains of the PI controller, $i_{S d}$ and $i_{S q}$ are the source current in the $d q 0$ domain, and $i_{S d, r e f}$ and $i_{S q, r e f}$ (derived from the measured DC voltage $V_{d c}$ of VOC rectifier) are the reference signals for $i_{S d}$ and $i_{S q}$, respectively. After obtaining the reference voltage $v_{d, r e f}$ and $v_{q, r e f}$, the inverse Park transformation, as shown in Equation (5), together with the PWM switching technique, are applied to derive the gate switching pulses $S_{a b c}$, which control the operation of the VOC rectifier. The overall domain transformation process involved in VOC operation is summarized in Figure 3.

$$
\left[\begin{array}{c}
v_{\alpha, \text { ref }} \\
v_{\beta, \text { ref }}
\end{array}\right]=\left[\begin{array}{cc}
\sin \theta & -\cos \theta \\
\cos \theta & \sin \theta
\end{array}\right]\left[\begin{array}{c}
v_{d, \text { ref }} \\
v_{q, \text { ref }}
\end{array}\right]
$$

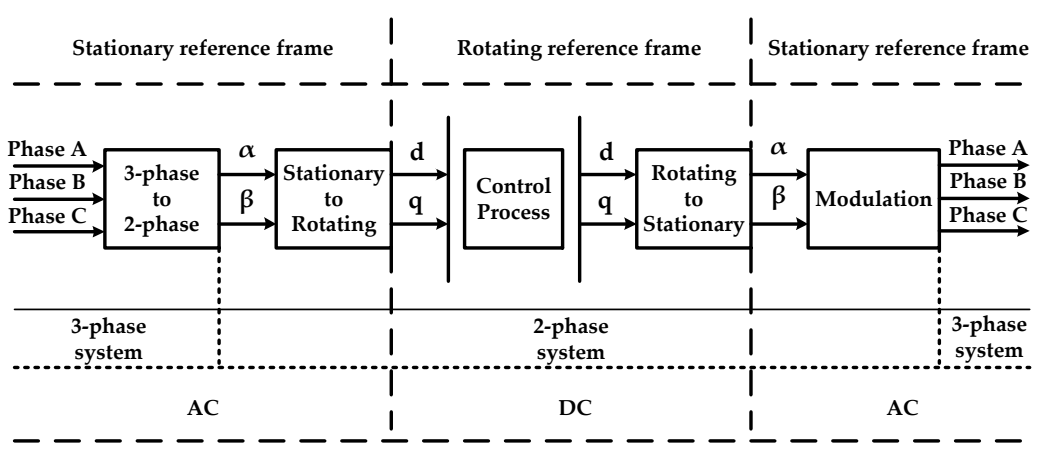

Figure 3. Overall domain transformation sequences involved in the VOC technique. 


\section{Methodology}

The proposed universal charger shown in Figure 4 is composed of a three-stage converter that is controlled by the VOC algorithm. The first stage consists of a three-phase AC source, a three-phase rectifier controlled by the VOC technique (named the VOC rectifier), and a DC-link capacitor. For closed-loop operation, the voltage and current controllers are used to obtain feedback voltage from the load-side battery of the EV. This is the most important control stage and consists of two main functions: (1) Regulating the output DC voltage to a pre-determined value, and (2) controlling the input AC phase currents to have a nearly sinusoidal wave shape and also to work in phase with the AC phase voltage.

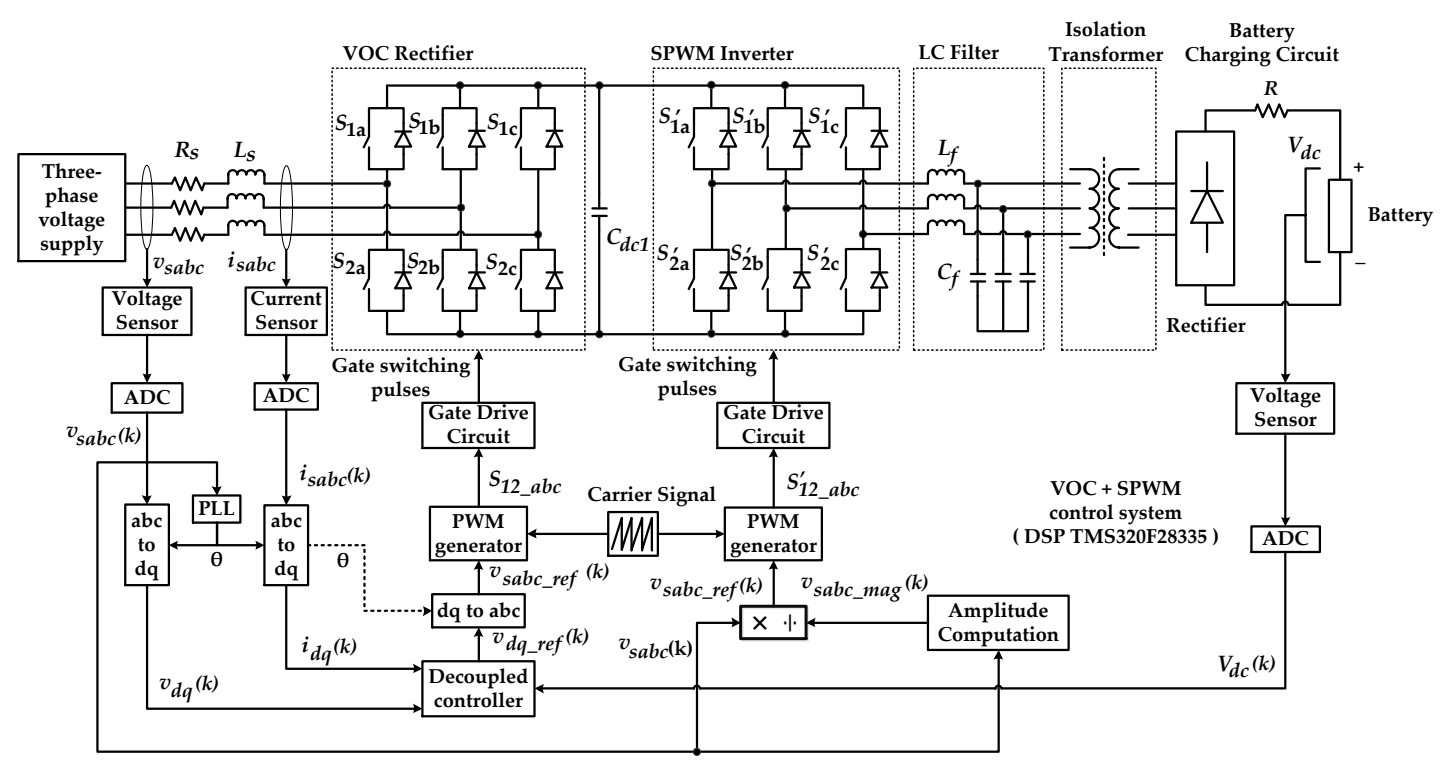

Figure 4. Overall circuit configuration of the universal charger with the signals of the control system.

The second stage contains an inverter controlled by the SPWM switching technique (named the SPWM inverter). The output of the PWM signal which has been filtered by the inductor-capacitor (LC) circuit, is further connected to a transformer (three-phase transformer of $50 \mathrm{~Hz}$ ) for either step-up or step-down purposes. Note that the inverter and rectifier share the same DC-link capacitor $C_{d c 1}$. Generally, the inverter produces a PWM waveform, with its width varying periodically. The PWM waveform is commonly filtered by an LC filter, which generates the desired sinusoidal waveforms. A high switching frequency provides a better filtered sinusoidal waveform. The desired output voltage is generated as a result of continuous changes in the amplitude and frequency of a reference or modulating voltage. The amplitude and frequency variations of the reference voltage will change continuously. This results in pulse-width patterns of the output voltage. However, the modulation pattern will remain sinusoidal.

The modulation process is executed by comparing a low-frequency sinusoidal modulating signal with a high-frequency triangular carrier signal. Pulses with varying duty cycles are formed when the two signals intersect with each other. The intersection locations determine the switching times for each switching state of a specific variable. As illustrated in Figure 4, three balanced-sinusoidal controlled voltages are compared with their respective triangular voltage waveforms. The resulting pulses are used to control the switching operating of the switching devices in each leg of the inverter. The switching frequency applied for the SPWM technique is set to $12 \mathrm{kHz}$. Basically, the switches in each phase are operating in a complementary manner: When the upper leg is in the open position, the lower leg will be in the closed position, and vice versa. The third stage is a three-phase diode bridge rectifier, where the control strategies of the whole charger are realized through VOC closed-loop control. 
The most important part of the proposed VOC technique is the applied decoupled controller, as shown in Figure 5. As can be observed in Figure 5, the proposed circuit utilizes three PI controllers. The first controller is a PI voltage controller which manages the output loop of DC-link voltage $V_{d c}$. This controller compares the measured $V_{d c}$ with its pre-determined reference value $V_{d c_{-} r e f}$ to estimate the reference current signal $i_{d_{-} r e f}$. The second controller is a PI current controller, which manages the inner loop of the $i_{d}$ current component. This minimizes the error between $i_{d}$ with $i_{d_{-} r e f}$ and then estimates the reference voltage signal $v_{d_{-} r e f}$. Similarly, another PI current controller is applied to manage the inner loop of the $i_{q}$ current component, where it reduces the $i_{q}$ current component to 0 and, in turn, estimates the reference voltage signal $v_{q_{-} r e f}$. Note that this control technique requires the three-phase AC current to be first transformed and decoupled into active $i_{d}$ and reactive $i_{q}$ components, respectively. The decoupled active and reactive components are then controlled in such a way that the errors between the desired reference and measured values of the active and reactive components are minimized. Generally, the active current component $i_{d}$ is regulated by using a DC-link voltage control approach which aims to achieve an active power flow balance in the system. Meanwhile, the reactive component $i_{q}$ is regulated to 0 to ensure unity power factor operation.

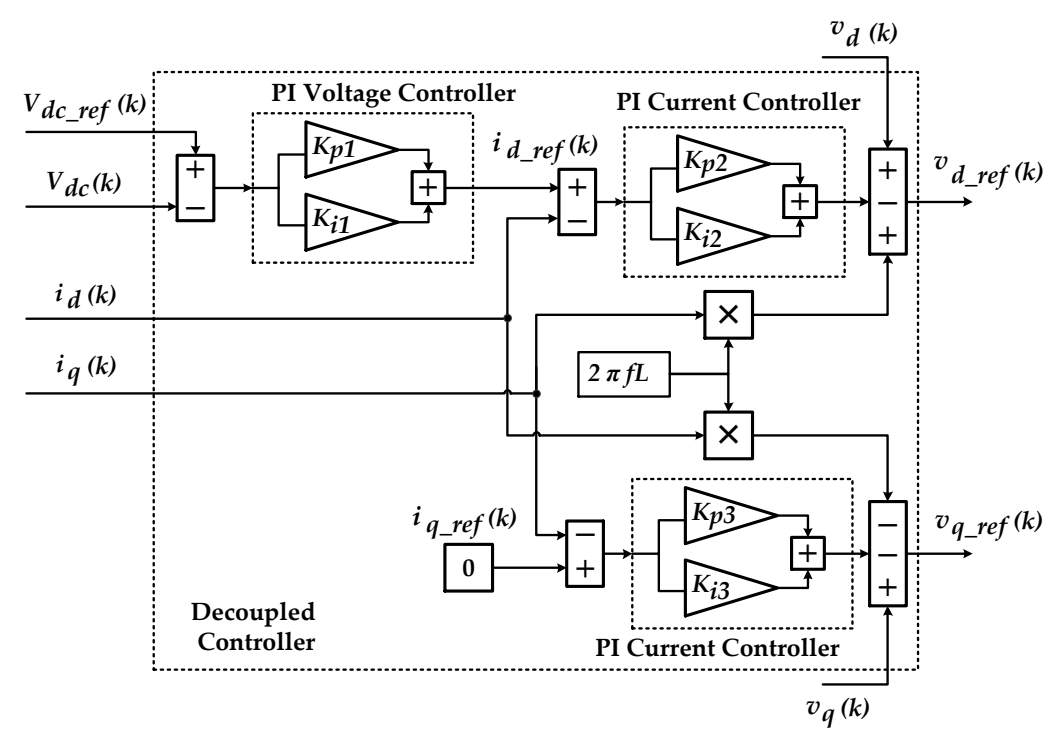

Figure 5. The control structure of the decoupled controller for the VOC technique.

The characteristics of the PI voltage controller and the two PI current controllers are given as follows:

$$
\begin{gathered}
i_{d_{-} r e f}=K_{p 1}\left(V_{d c_{-} r e f}-V_{d c}\right)+K_{i 1} \int\left(V_{d c_{-} r e f}-V_{d c}\right) d t \\
v_{d_{-} r e f}=v_{d}+2 \pi f L_{s} \quad i_{q}-\left(K_{p 2}\left(i_{d_{r e f}}-i_{d}\right)+K_{i 2} \int\left(i_{d_{r e f}}-i_{d}\right) d t\right) \\
v_{q_{-} r e f}=v_{q}-2 \pi f L_{s} i_{d}-\left(K_{p 3}\left(0-i_{q}\right)+K_{i 3} \int\left(0-i_{q}\right) d t\right)
\end{gathered}
$$

where $K_{p 1}$ and $K_{i 1}$ are the constant gain values that represent the proportional and integral gains of the PI voltage controller, respectively; $K_{p 2}$ and $K_{i 2}$ are the gain values for the first PI current controller; $K_{p 3}$ and $K_{i 3}$ are the gain values for the second PI current controllers; and $L_{S}$ is the source inductance value. For these inner current control loops, the bandwidth $\alpha_{i}$ should be selected as smaller than a decade below the switching frequency $\left(f_{s}\right)$ [25]. 


$$
\begin{gathered}
\alpha_{i}<2 \pi \frac{f_{s}}{10} \\
K_{p 2}=K_{p 3}=\alpha_{i} L_{s} \text { and } K_{i 2}=K_{i 3}=\alpha_{i} R_{s}
\end{gathered}
$$

where $\alpha_{i}(\mathrm{rad} / \mathrm{s})$ is the current controller bandwidth.

For a voltage control loop, the conversational DC link capacitor is used to tune the PI controller as follows [26,27]:

$$
K_{p 1} \geq C_{d c 1} \varsigma w \text { and } K_{i 1} \geq C_{d c 1} \varsigma w / 2
$$

where the damping factor $\varsigma$ is fixed at 0.707 , and $w$ is the angular frequency. Subsequently, by using the initial value, further tuning and adjustment are performed heuristically to improve the performance of the proposed charging strategy.

\section{Simulation and Experimental Setup}

In this work, the simulation of the proposed EV universal charger and its control algorithms were conducted in the MATLAB/Simulink 2010a software, utilizing the SimPowerSystems toolbox. The charger circuit in the MATLAB/Simulink software is shown in Figure 6. The main components of the circuit are capacitors, inductors, insulated-gate bipolar transistor (IGBT) switches, a three-phase transformer, and a battery as a load. The simulation parameters of the charger are listed as follows:

\section{(1) Input Source Parameters}

The circuit consists of a three phase input power supply $v_{a}, v_{b}$, and $v_{c}$. The three-phase AC input voltage has been supplied to various values of voltage, which depend on the level of charging at a frequency of $50 \mathrm{~Hz}$. The input filter consists of inductors and resistors that are connected in series, where the input inductors $\left(L_{S a}, L_{S b}\right.$, and $\left.L_{S c}\right)$ are $5 \mathrm{mH}$, and the input resistors $\left(R_{S a}, R_{S b}\right.$, and $\left.R_{S c}\right)$ are $5 \Omega$. The input filter has been connected to the input of the next part of the circuit (PWM rectifier).

\section{(2) PWM VOC Rectifier}

This consists of three phases: The AC source, VOC rectifier, and DC-link capacitor. For closed-loop operation, the voltage and current controllers are used to obtain feedback voltage from the load-side battery of the electric vehicles. The purposes of the control are as follows:

i. Control the DC-link voltage to a pre-determined voltage level.

ii. Control the input AC phase currents so that they have a nearly sinusoidal wave shape and also work in phase with the AC phase voltages.

\section{(3) PI Controller}

This work presents three PI controllers to control three elements: $i_{d}, i_{q}$ currents, and DC-link voltage. At this point, the PI controller is used for the control of the input current and output voltage. A proportional $(\mathrm{P})$ controller reduces error in response to disturbances (transients) but still allows for a steady-state error. When the controller includes a term proportional to the integral of the error (I), the steady-state error will be eliminated. Dynamic response is defined as the output overshoot that occurs when the converter output load is turned on/off or abruptly changed. In this work, a PI controller for efficient operation voltage and current PI controllers were used for controlling the input current and output voltage.

\section{(4) PWM Inverter}

A PWM inverter is composed of six switches $S_{1}$ through $S_{6}$, and the output of the inverter for each phase is connected at the middle of each inverter leg. The output of the comparators provides 
the gating pulses required for controlling the switching operation of all three legs in the inverter. The switching frequency applied for the PWM was set at $12 \mathrm{kHz}$. Basically, the switches in each phase are operating in a complementary manner: When the upper leg is in the open position, the lower leg will be in closed position, and vice versa.

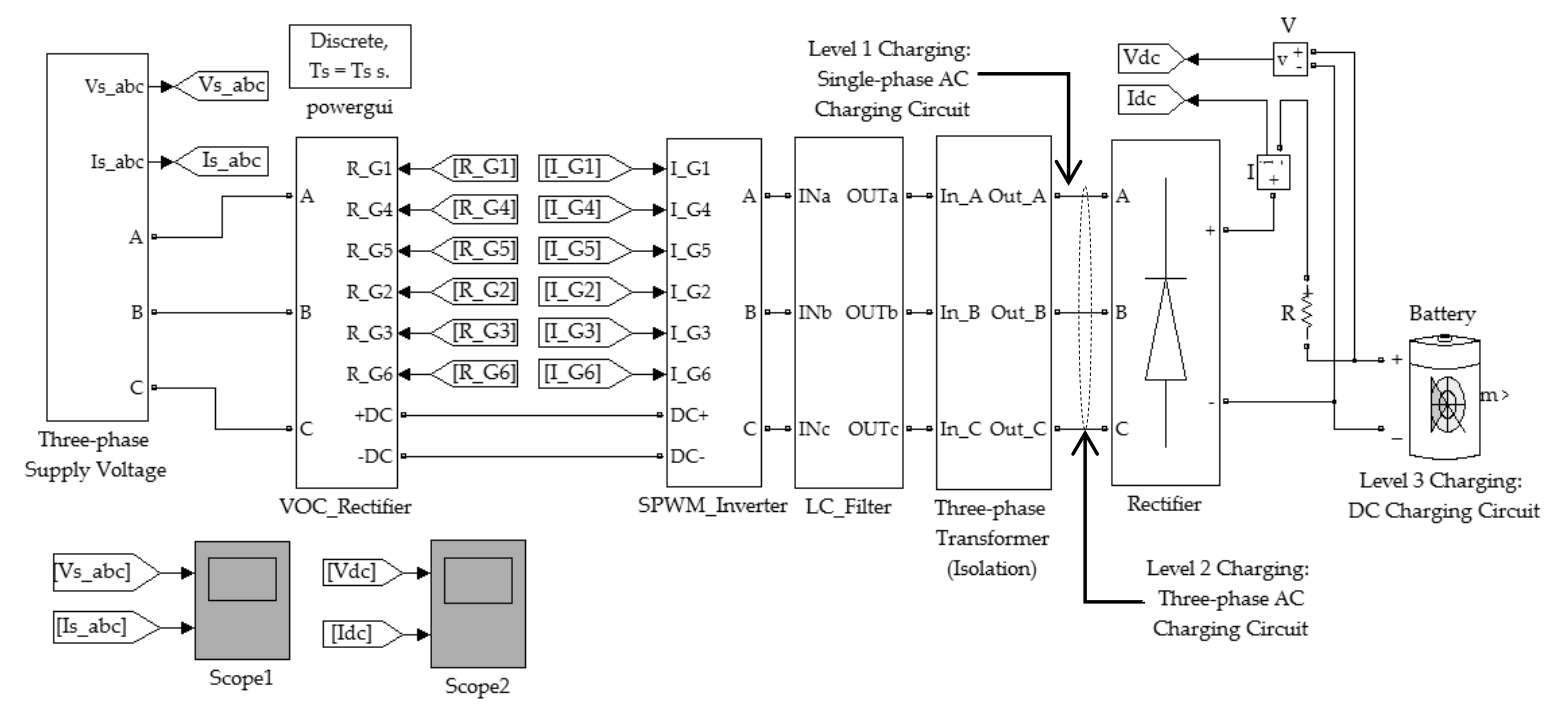

Figure 6. Overall simulation model for the proposed universal battery charger.

With the completion of the simulation work, the next step was developing the experimental setup to evaluate the performance of the proposed technique. A hardware prototype of the charger was built, as shown in Figure 7. Laboratory prototypes were constructed where the controller and power electronics circuits were constructed to function as three-level chargers, similar to the one modeled in MATLAB/Simulink. The experimental set up consisted of the measurement circuit implementation, driver circuits, and a digital signal processor (DSP) board. The current and voltage sensors were developed to measure the DC current and voltage of the power supply. This research study used a current sensor of (LA-125P) and a voltage sensor of (LV-25P). All of the signals used by the VOC PWM rectifier and the SWPM inverter were processed through a DSP. The power switching device of the VOC rectifier and SPWM inverter is a module IGBT (CM200DU-24F), which needs to be isolated from a digitally based circuit or, specifically, a DSP. Thus, for this purpose, a driver circuit was designed by using an optocoupler of (LM4041C12ILP). However, in experimental work, for safety purposes and also due to resource limitations, the maximum input supply voltage for the battery charger was set to $100 \mathrm{Vrms}$ (line to line). Meanwhile, the output DC reference voltage was set to $100 \mathrm{~V}$. The proposed control scheme was implemented on a DSP controller (TMS320F28335), where it is can easily interface with the MATLAB/Simulink software. More importantly, the specification of this DSP model was sufficient for this work, as it provided a maximum clock frequency of $150 \mathrm{MHz}$ and came with $16 \mathrm{ADC}$ channels (used as input) and 12 enhanced pulse width modulator (ePWM) channels (used as output). Figure 8 shows the MATLAB/Simulink model that was developed for DSP implementation. The first controller program was the ADC (Analog-to-Digital Converter) block, where the digital resolution of the converted signal was 12 bits. The output of ADC was in the range of $0-4095$ because the ADC is a 12-bit converter. Finally, the ePWM block generated the ePWM. To control the switching operation of all the power converters, the control outputs of the DSP were interfaced to their respective switches via driver circuits. 


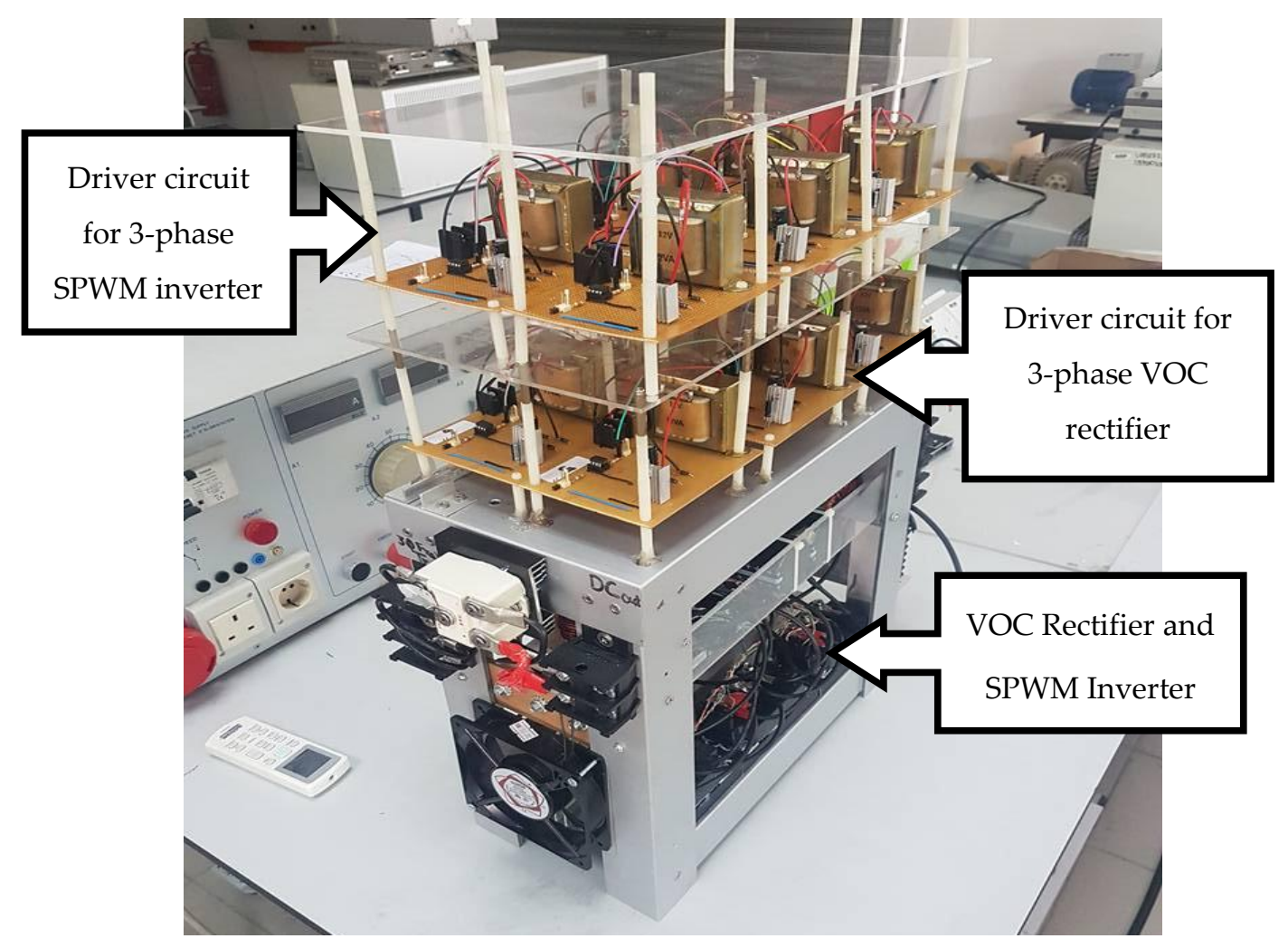

Figure 7. Experimental setup of EV universal charger circuits.

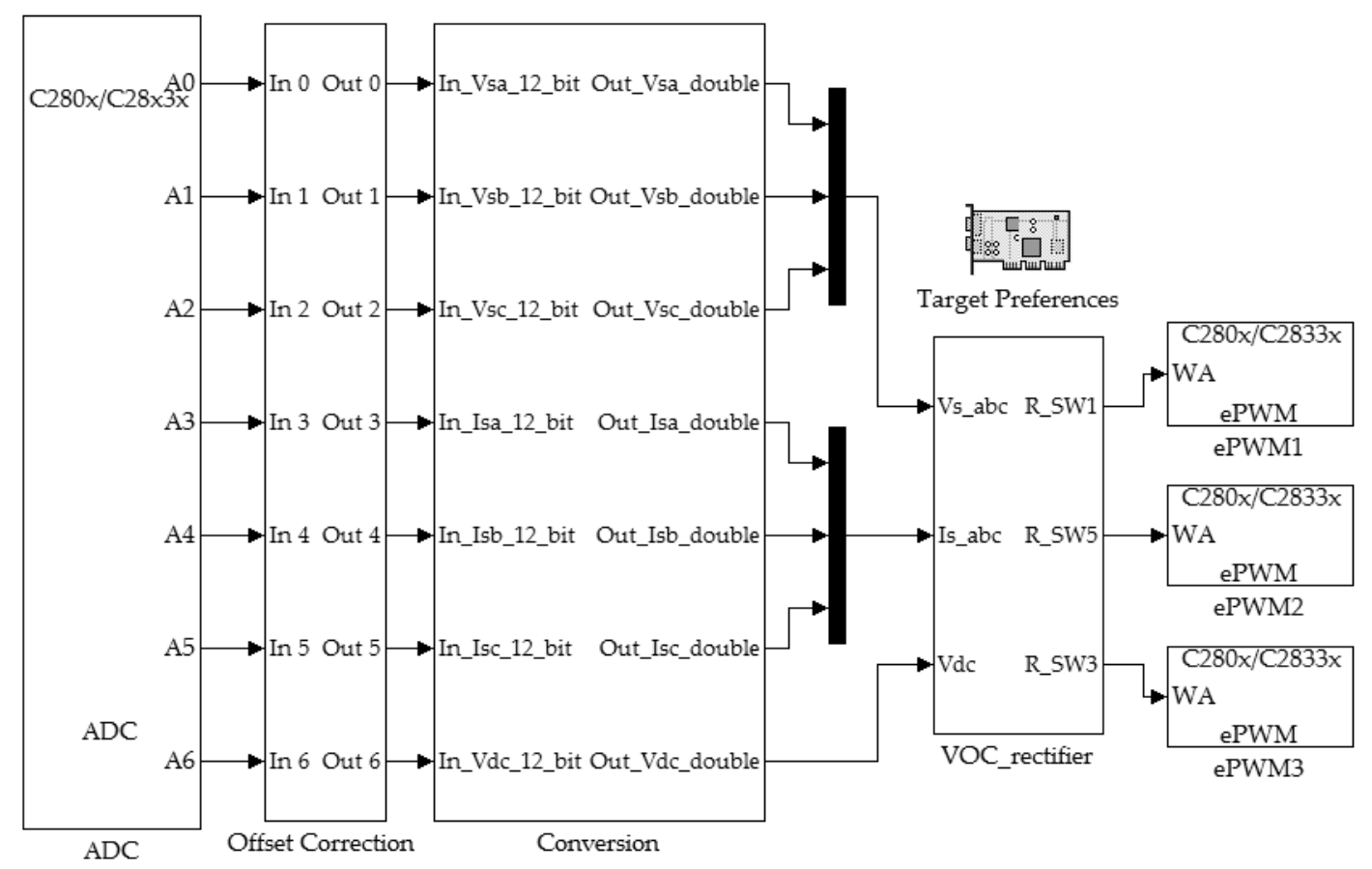

(a)

Figure 8. Cont. 


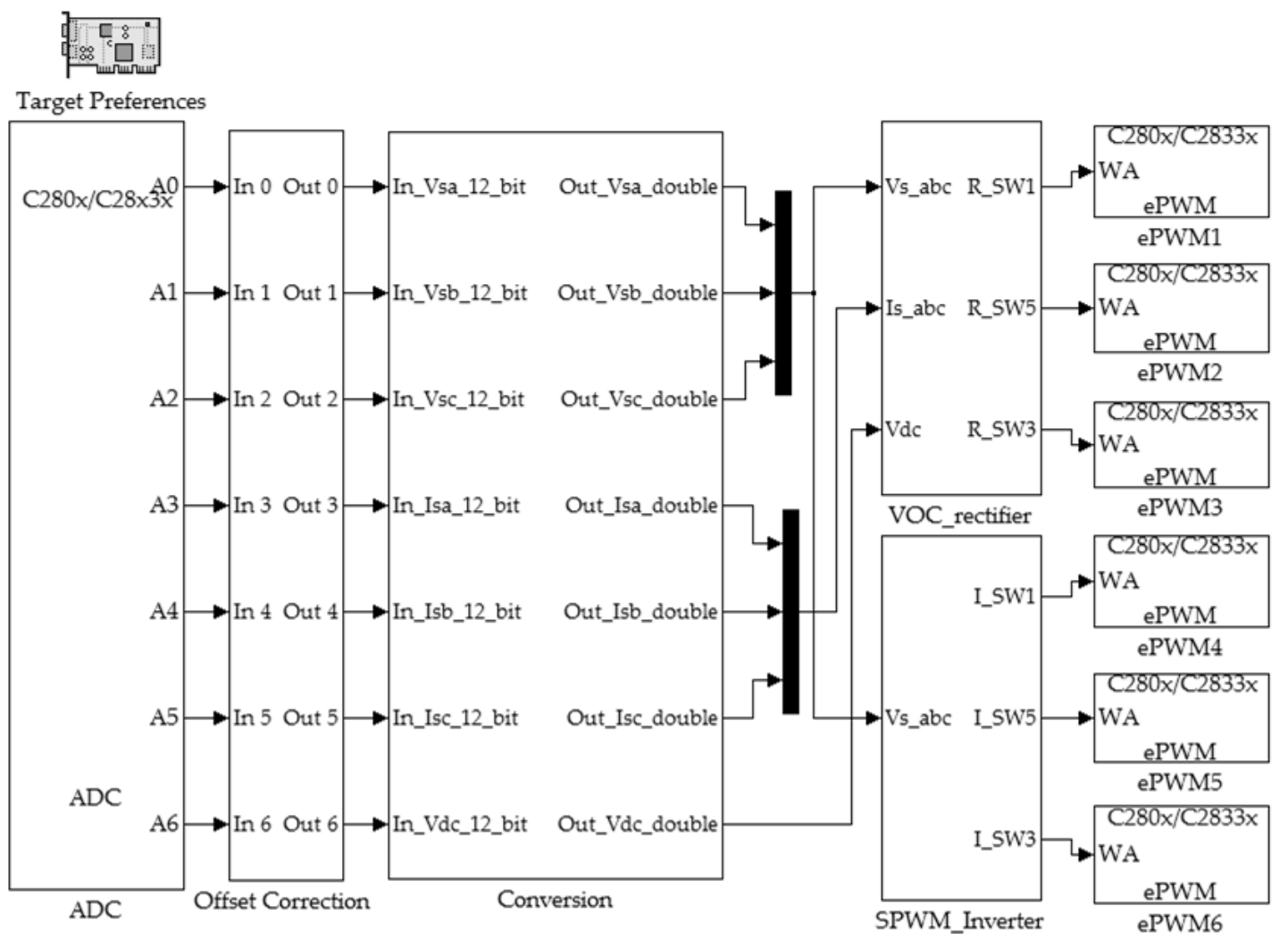

(b)

Figure 8. Simulation model of digital signal processor (DSP) implementation: (a) The control algorithm of PWM rectifier and (b) the control algorithm of the sinusoidal pulse-width modulation (SPWM) inverter.

\section{Simulation Results}

This section presents all the simulation findings obtained for this work. The performance of the proposed universal EV charger is evaluated for Levels 1, 2, and 3 of the charging standard.

\subsection{Level 1 Charging}

For Level 1 charging, the proposed EV charger was tested for its effectiveness in providing sinusoidal output current, which can be applied for single-phase battery charging. The simulation parameters applied for this part of the work are summarized in Table 1.

Table 1. Parameter specifications for Level 1 charging.

\begin{tabular}{cccc}
\hline Parameter & Symbol & Unit & Value \\
\hline Resistance load & $R_{\text {load }}$ & $\Omega$ & 20 \\
Input inductance filter & $L_{f}$ & $\mathrm{mH}$ & 5 \\
DC-link capacitor & $C_{d c 1}$ & $\mu \mathrm{F}$ & 2200 \\
Grid voltage frequency & $f$ & $\mathrm{~Hz}$ & 50 \\
Switching frequency & $f_{s}$ & $\mathrm{kHz}$ & 12 \\
Input resistance filter & $R_{f}$ & $\Omega$ & 5 \\
Input voltage & $V_{i n}$ & $\mathrm{~V}$ & 120 \\
Voltage controller & $K_{p 1}$ & - & 0.00077 \\
Voltage controller & $K_{i 1}$ & - & 0.017 \\
Current controller & $K_{p 2}$ and $K_{p 3}$ & - & 67 \\
Current controller & $K_{i 2}$ and $K_{i 3}$ & - & $1.7 \times 10^{4}$ \\
\hline
\end{tabular}


The simulation results obtained for Level 1 charging are shown in Figure 9. As can be seen from Figure 9, the output current obtained was in sinusoidal shape with a THD value of less than 5\%, complying with Institute of Electrical and Electronics Engineers (IEEE) standard 519. Moreover, by comparing Figure 9a,b, it is clear that the EV charger with LC filtering was able to provide a sinusoidal output current with a lower THD value of $2.48 \%$. The result of the THD was obtained by using fast Fourier transform (FFT) analysis with a fundamental frequency of $50 \mathrm{~Hz}$. In contrast, without the LC filter, the performance of the EV charger was unacceptable with an output current of a high THD value of $13.41 \%$ recorded. In other words, the LC filter was able to further reduce the THD value by $10.93 \%$. The maximum peak of the input current was recorded as $23 \mathrm{~A}$ per phase.
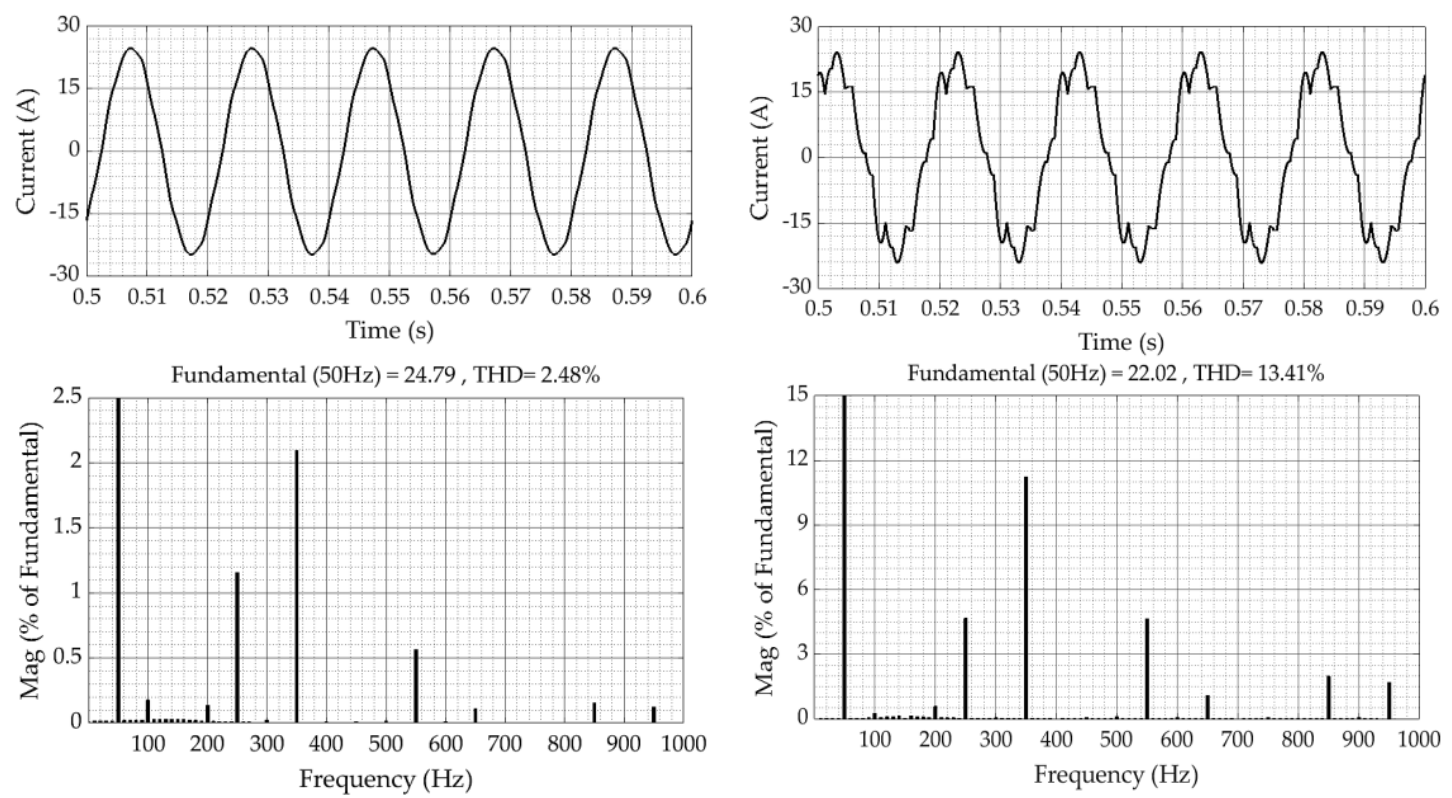

(a)

(b)

Figure 9. The output current obtained for Level 1 charging: (a) With LC filtering and (b) without LC filtering.

\subsection{Level 2 Charging}

For Level 2 charging, the proposed EV charger was tested for its effectiveness in providing a sinusoidal output current, which can be applied for three-phase battery charging. The simulation parameters applied for this part of the work are summarized in Table 2. The simulation results obtained for Level 2 charging are shown in Figures 10 and 11. As can be seen from Figure 10, the output current obtained for all the phases had a sinusoidal shape with a THD value less than $5 \%$, complying with IEEE standard 519. The maximum peak value of the input current was recorded to be approximately 75 A per phase. Moreover, Figure 11 shows the waveform obtained for the input current. Based on Figure 11, it is clear that the proposed control scheme was able to maintain the THD of the input current at $2.23 \%$, thus leading to an almost unity power factor. In other words, the proposed universal $\mathrm{EV}$ charger is able to provide effective charging without causing any noticeable harmonic distortion to the connected grid. 
Table 2. Parameter specifications for Level 2 charging.

\begin{tabular}{cccc}
\hline Parameter & Symbol & Unit & Value \\
\hline Resistance load & $R_{\text {load }}$ & $\Omega$ & 60 \\
Input inductance filter & $L_{f}$ & $\mathrm{mH}$ & 5 \\
DC-link capacitor & $C$ & $\mu \mathrm{F}$ & 2200 \\
Grid voltage frequency & $f$ & $\mathrm{~Hz}$ & 50 \\
Switching frequency & $f_{s}$ & $\mathrm{kHz}$ & 12 \\
Input resistance filter & $R_{f}$ & $\Omega$ & 5 \\
Input voltage & $V_{i n}$ & $\mathrm{~V}$ & 240 \\
Voltage controller & $K_{p 1}$ & - & 0.0077 \\
Voltage controller & $K_{i 1}$ & - & 67 \\
Current controllers & $K_{p 2}$ and $K_{p 3}$ & - & 0.017 \\
Current controllers & $K_{i 2}$ and $K_{i 3}$ & - & $1.7 \times 10^{3}$ \\
\hline
\end{tabular}
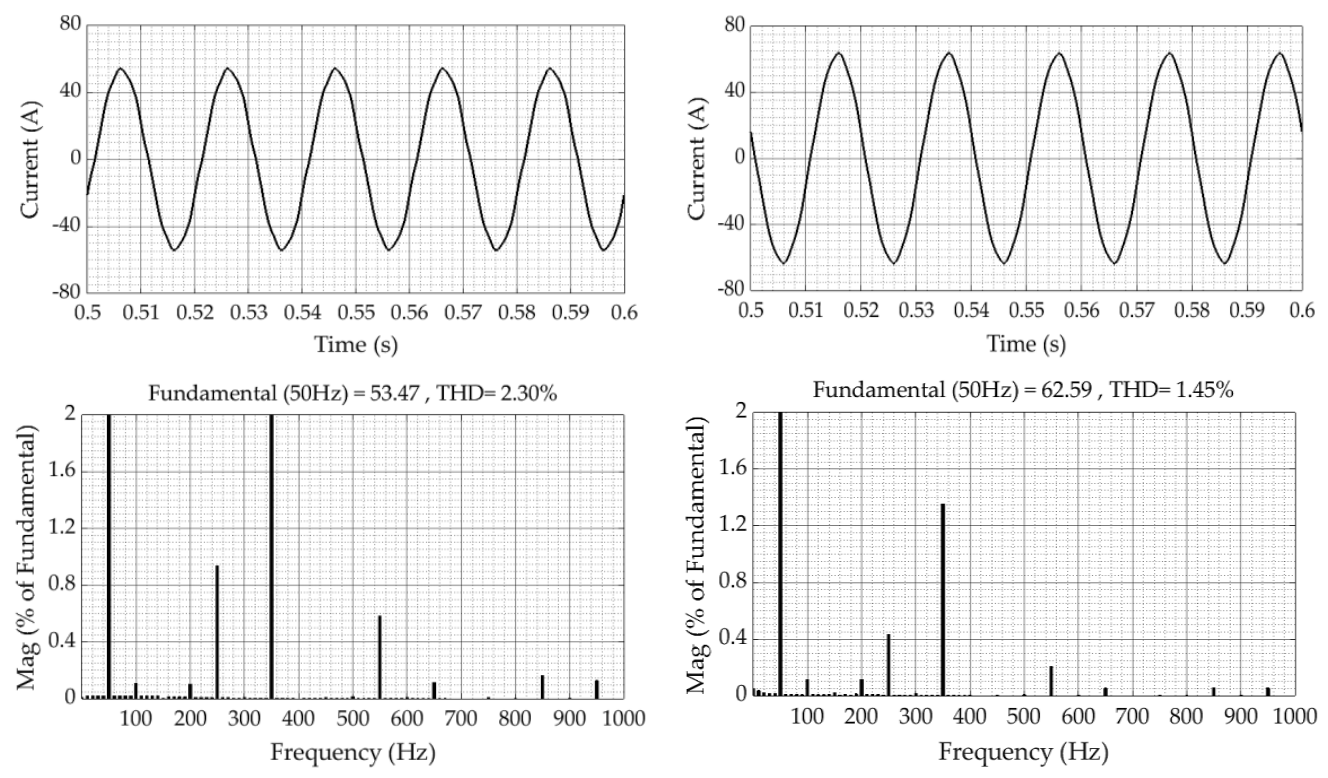

(a)

(b)
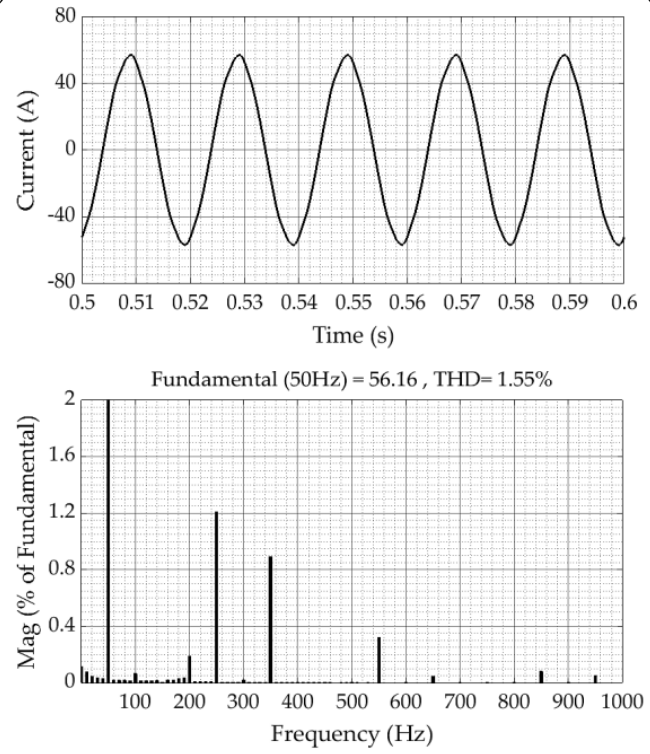

(c)

Figure 10. The output current of the charger for Level 2 charging: (a) Phase A, (b) Phase B, and (c) Phase C. 

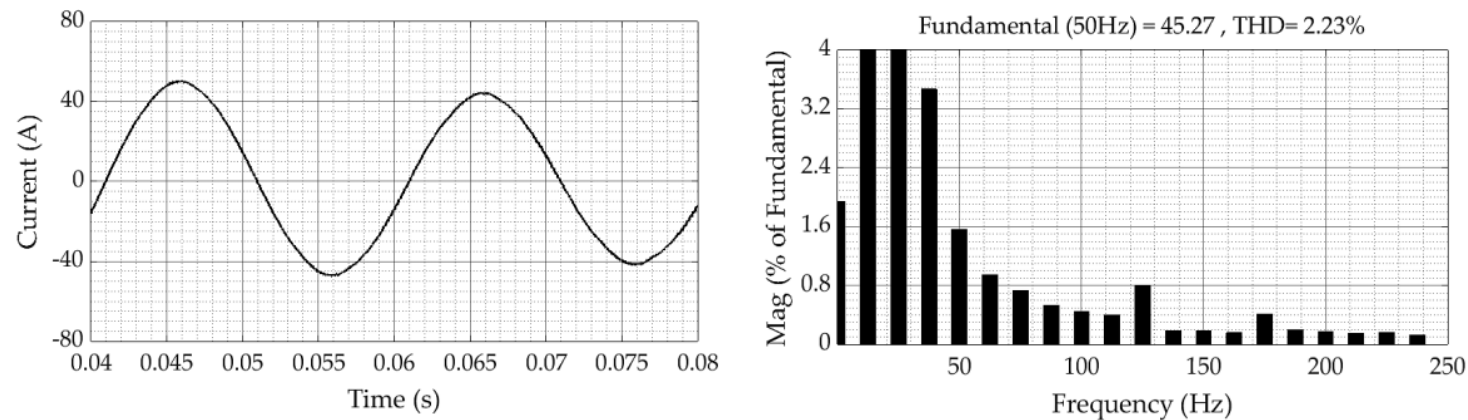

Figure 11. The input current waveform for Level 2 charging (Phase A).

\subsection{Level 3 Charging}

For Level 3 charging, the proposed EV charger was tested for its effectiveness at providing a constant output DC current that can be directly applied for DC battery charging. The simulation parameters applied for this part of work are summarized in Table 3. Three types of batteries: Nickel metal, lithium ion, and lead acid were used to test the charging performance of the proposed charger. The simulation results obtained for Level 3 charging are shown in Figures 12-14.

Table 3. Parameter specifications for Level 3 charging.

\begin{tabular}{cccc}
\hline Parameter & Symbol & Unit & Value \\
\hline Input inductance filter & $L_{f}$ & $\mathrm{mH}$ & 5 \\
Battery & $B$ & $\mathrm{AH}$ & $50 \%$ \\
Grid voltage frequency & $f$ & $\mathrm{~Hz}$ & 50 \\
Switching frequency & $f_{s}$ & $\mathrm{kHz}$ & 12 \\
Input resistance filter & $R_{f}$ & $\Omega$ & 5 \\
Input voltage & $V_{i n}$ & $\mathrm{~V}$ & 400 \\
Reference voltage & $V_{d c}$ & - & 650 \\
Voltage controller & $K_{p 1}$ & - & 0.00027 \\
Voltage controller & $K_{i 1}$ & - & 0.017 \\
Current controllers & $K_{p 2}$ and $K_{p 3}$ & - & 67 \\
Current controllers & $K_{i 2}$ and $K_{i 3}$ & & $1.7 \times 10^{4}$ \\
\hline
\end{tabular}

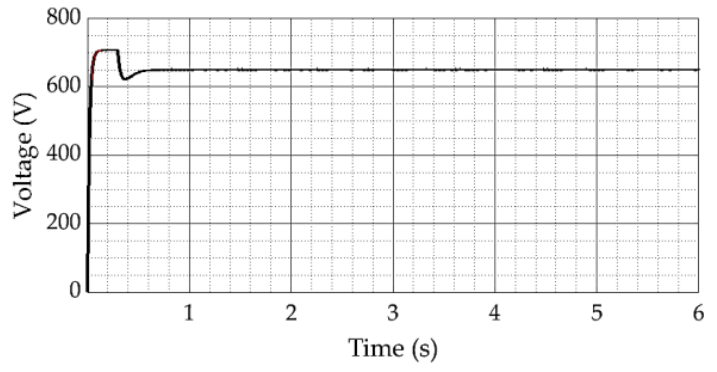

(a)

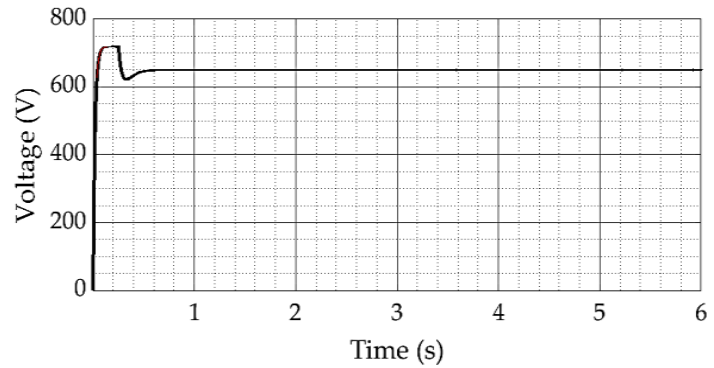

(b)

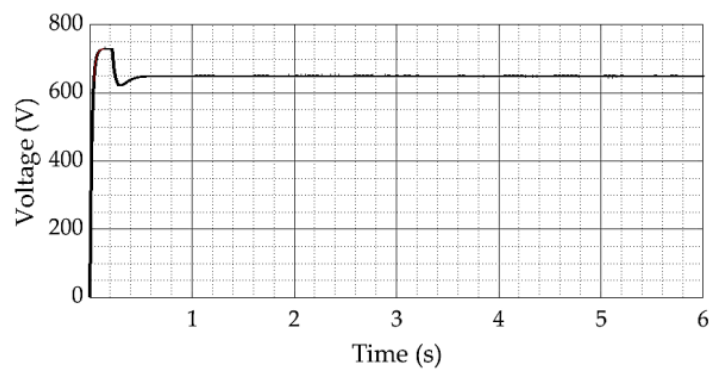

(c)

Figure 12. The output DC-link voltage of Level 3 charging for (a) nickel metal, (b) lithium ion, and (c) lead acid batteries. 
Based on Figure 12, it can be observed that the proposed EV charger was able to maintain the output DC charging voltage at the desired level of $650 \mathrm{~V}$ for all three types of battery charging. Meanwhile, as can be observed in Figure 13, the DC charging current for all three types of battery charging has also been successfully maintained at a constant value of approximately 120 A. Hence, from the findings, it can be confirmed that the regulated DC voltage and DC current are able to fulfill the requirements of Level 3 DC fast charging for an electric bus or lorry. The findings obtained also show the flexibility of the proposed EV charger, as it can be applied to charge three types of batteries which include nickel metal, lithium ion, and lead acid batteries.

More importantly, as can be observed from Figure 14, it is clear that the proposed control scheme is able to maintain the THD of the input current at $0.39 \%$ while performing the DC charging, thus leading to an almost unity power factor. Once again, the proposed universal EV charger is proven to provide effective DC charging without causing any noticeable harmonic distortion to the connected grid.

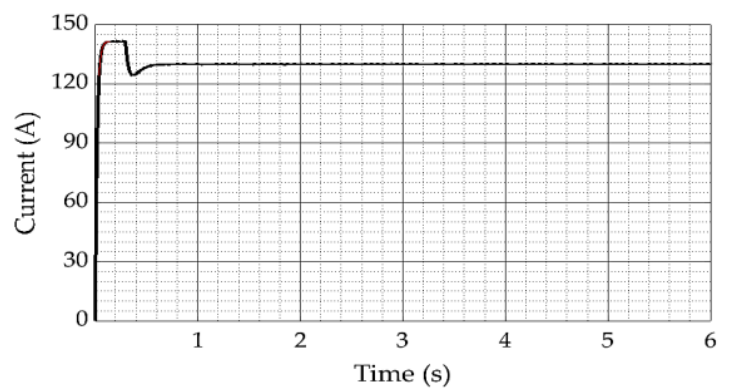

(a)

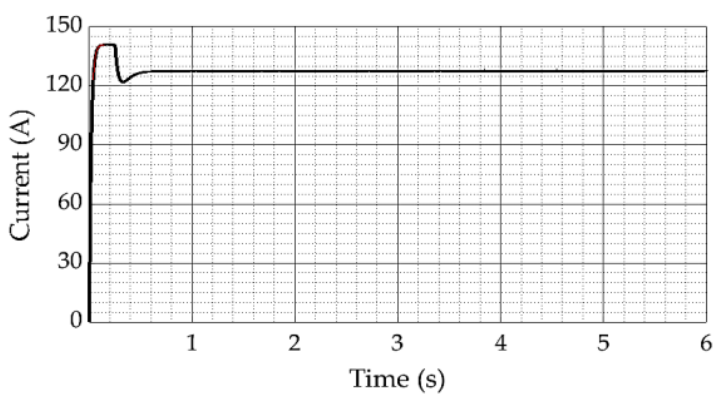

(b)

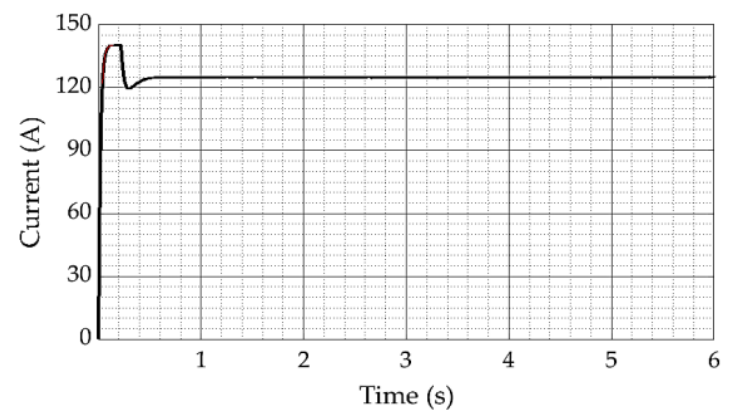

(c)

Figure 13. The output DC current of Level 3 charging for (a) nickel metal, (b) lithium ion, and (c) lead acid batteries.
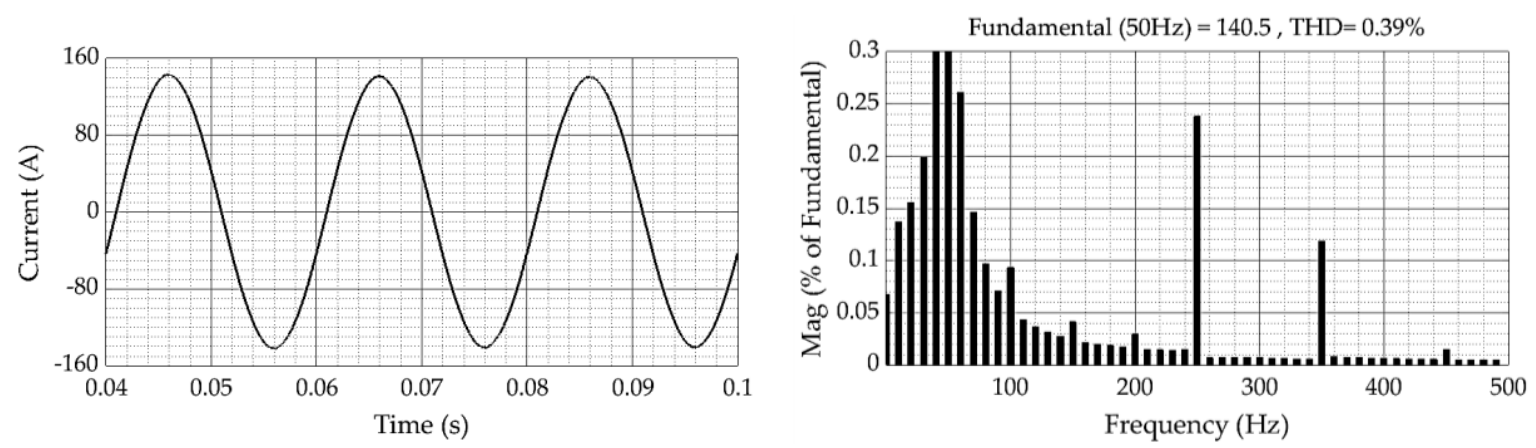

Figure 14. The input current waveform for Level 3 charging (Phase A).

\section{Experimental Results}

For experimental work, the proposed universal charger was only tested for its ability to provide constant DC charging. The experimental results show the steady-state waveforms for input source 
voltage, input source current, and DC output voltage and current; these results are provided in Figure 15. As can be observed in Figure 15, the input voltage and current waveforms for all three phases exhibit a sinusoidal wave shape. Moreover, the output DC voltage is observed to be continuously maintained at a fixed value close to the reference value of $100 \mathrm{~V}$. With a constant DC output voltage, the proposed charger is able to provide a DC output current of up to $9 \mathrm{~A}$ while charging a lead acid battery.

$$
\begin{array}{ll}
v_{s a} & (200 \mathrm{~V} / \mathrm{div}) \\
V_{d c} & (200 \mathrm{~V} / \mathrm{div}) \\
I_{d c} & (20 \mathrm{~A} / \mathrm{div}) \\
i_{s a} & (20 \mathrm{~A} / \mathrm{div})
\end{array}
$$
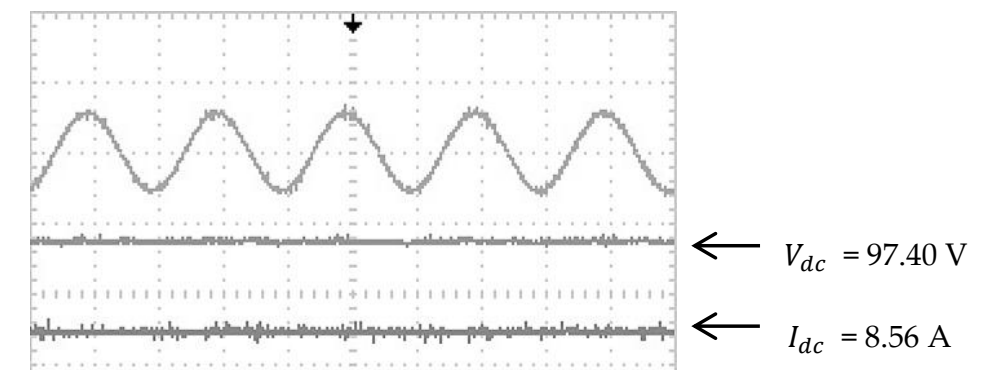

$v_{s b}(200 \mathrm{~V} / \mathrm{div})$

$V_{d c}(200 \mathrm{~V} / \mathrm{div})$

$I_{d c} \quad(20 \mathrm{~A} / \mathrm{div})$

$i_{s b}(20 \mathrm{~A} / \mathrm{div})$

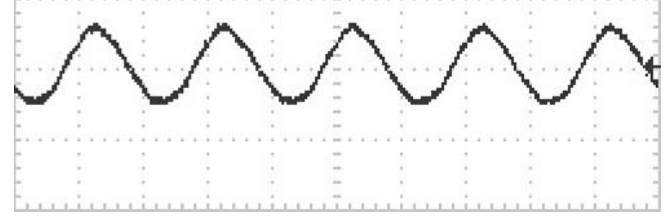

(a) Time $(10 \mathrm{~ms} / \mathrm{div})$

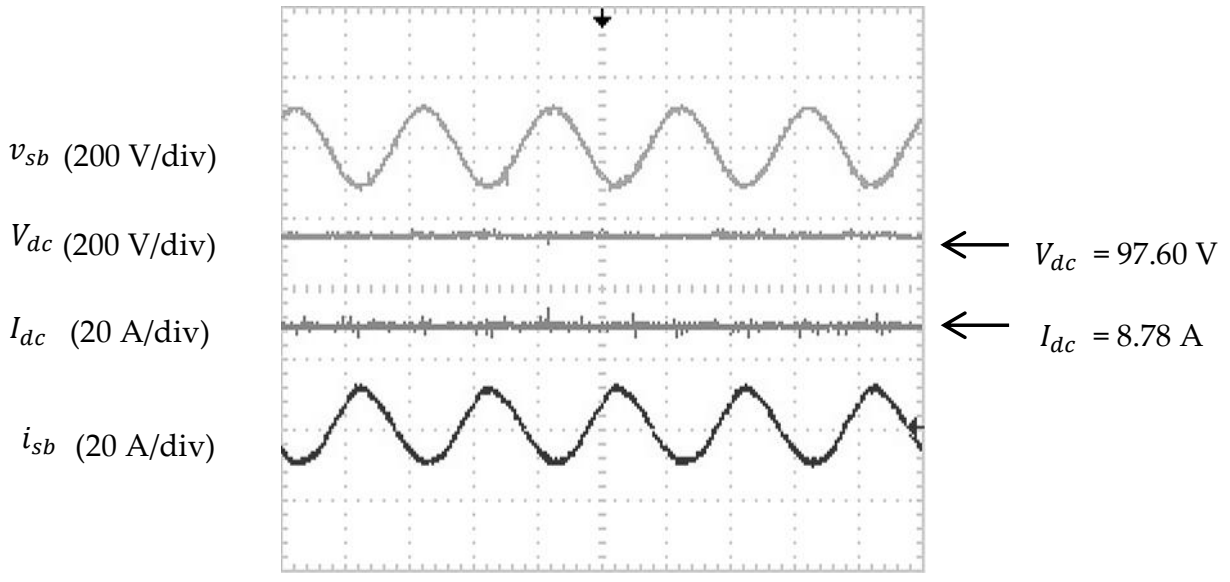

(b) Time (10 ms/div)

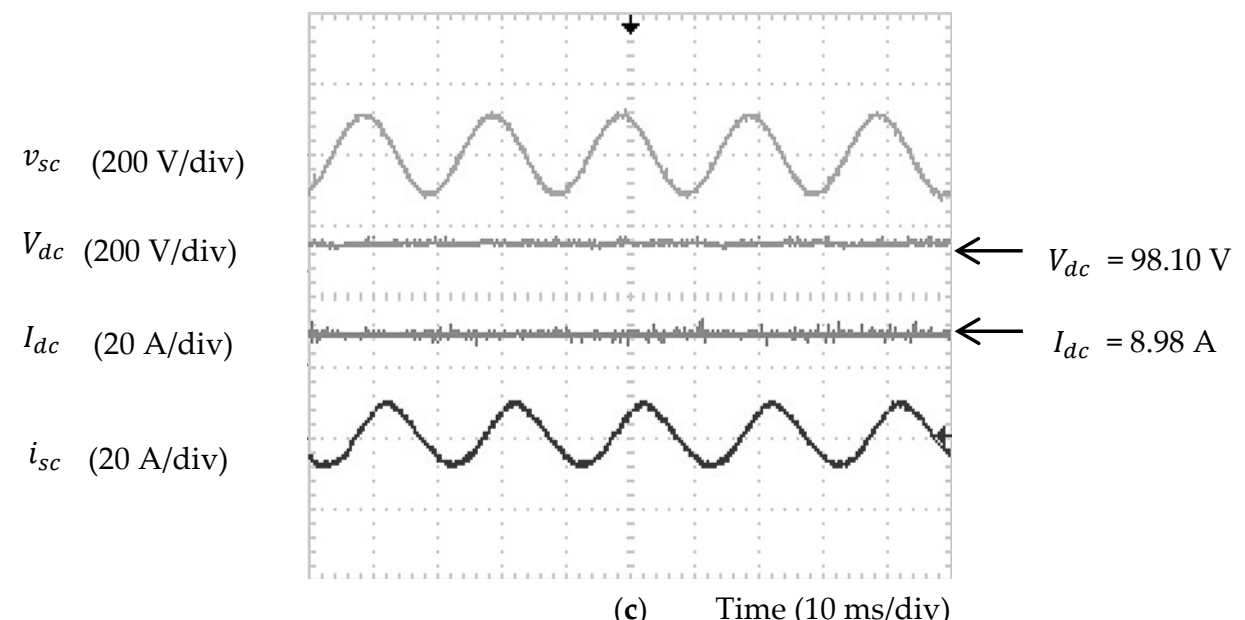

(c) Time $(10 \mathrm{~ms} / \mathrm{div})$

Figure 15. The input phase voltage, input phase current, output DC charging current, and output DC charging voltage provided by the charger: (a) Phase A, (b) Phase B, and (c) Phase C. 
On the other hand, Figure 16 shows the THD value obtained for Phase A input current. As can be seen in Figure 16, the THD was recorded as 1.85\%, which complies with the limit of $5 \%$ set by IEEE standard 519. In addition, the input current was observed to be working in-phase with the input voltage, which led to the maximum power factor. Hence, based on the results obtained, the proposed charger is confirmed to provide effective DC charging without causing any noticeable harmonic distortion to the connected grid. Note that the $v_{S_{\_} r e f}$ waveform, as shown in Figure 16, is the reference signal used for synchronizing the operating phase of the proposed charger with the connected grid. Hence, the $v_{s_{-} r e f}$ waveform can be observed to have the same phase as the measure input voltage waveform.

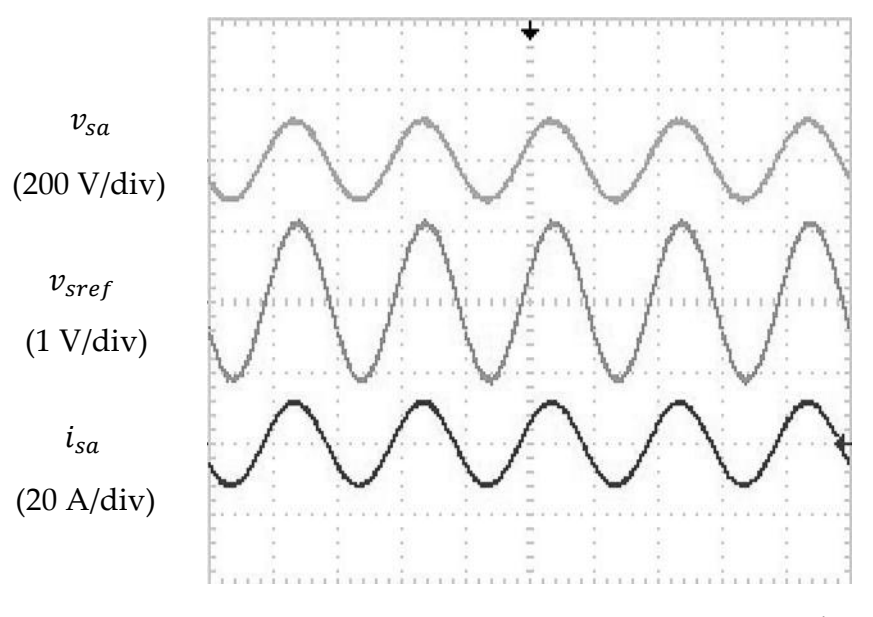

(a)

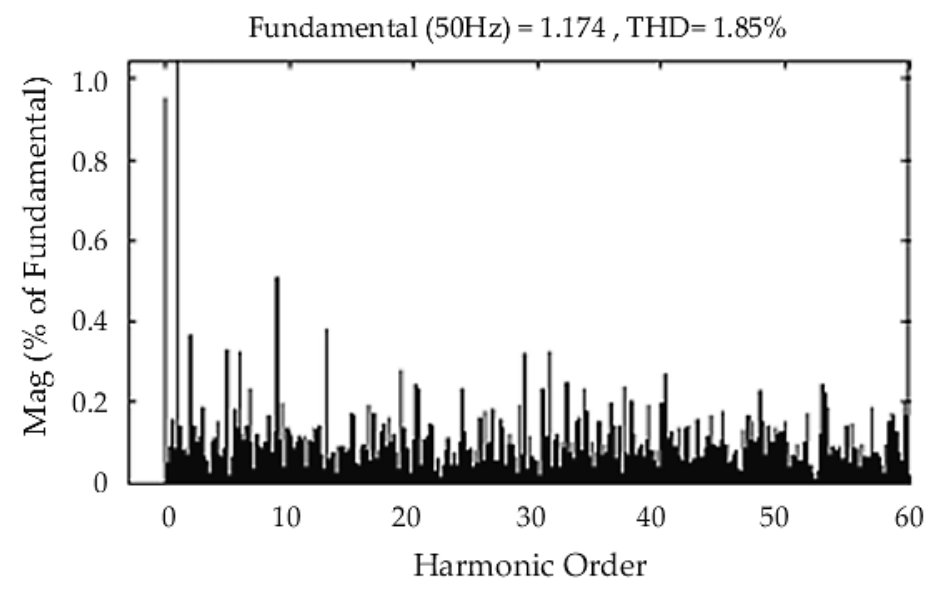

(b)

Figure 16. Experimental results obtained, which include: (a) Phase A input voltage, reference voltage, input current, and (b) total harmonic distortion (THD) of input current.

\section{Benchmarking}

The proposed three-level universal EV charger was designed to overcome the limitations of the charging system in the previous work. The fundamental operation has been described, analyzed, and verified by simulations and experimental work in the previous sections. In this section, the features of the proposed charger are benchmarked with the capability of the few existing works. Table 4 summarizes the performance of the proposed charger in comparison to a few existing charging systems, which include a boost converter, a non-isolation DC-DC converter, and a unidirectional charger. The comparison considers the complexity of the control structure, the THD performance, the integration of the isolation system, and the allowable level of charging standards. As summarized 
in Table 4, the proposed universal charger operated by the VOC control technique provides the best advantages in terms of controller complexity and THD performance. Additionally, the integration of a three-phase transformer in the proposed charger allows for isolation between the grid and vehicle and, thus, potentially reduces the damage to the charger/vehicle due to power quality issues that occurred at the main supply. Most importantly, the proposed universal charger is able to provide all three levels of charging (Levels 1, 2 and 3), whereas the existing charger only permits single-level charging (i.e., either Level 1 or 2).

Overall, as reported by the simulation and experimental results, the design concept of the proposed universal EV charger itself and, subsequently, the operation of the VOC and SPWM algorithms in a control system, can be confirmed to be valid. The proposed universal EV charger is designed to perform three types of charging: Single-phase AC charging (Level 1), three-phase AC charging (Level 2), and DC charging (Level 3). Furthermore, the proposed VOC and SPWM control techniques are applied to minimize the harmonic distortion in the grid. As can be seen from the simulation and experimental work, the THD value is well below $5 \%$. In other words, the proposed charging strategy does not cause significant harmonic distortions to the grid while charging.

Table 4. The performance of the proposed charger compared with previous charging systems.

\begin{tabular}{cccccc}
\hline Charger Type & Control Method & $\begin{array}{c}\text { Control } \\
\text { Structure }\end{array}$ & THD & Isolation & $\begin{array}{c}\text { Level of } \\
\text { Charging }\end{array}$ \\
\hline Boost Converter [22] & Digital Control & Simple & $1.4 \%$ & Yes & Level 2 \\
\hline Non-isolation converter [21] & Bidirectional Converter (BDC) & Complex & $2.9 \%$ & No & Level 1 \\
\hline Unidirectional charger [23] & Direct Power Control (DPC) & Very complex & $4.95 \%$ & No & Level 2 \\
\hline Proposed charger & VOC and SPWM technique & Very simple & $0.83 \%$ & Yes & Levels 1, 2 and 3 \\
\hline
\end{tabular}

\section{Conclusions}

In this research, the proposed three-level universal electric vehicle charger was successfully designed, fabricated, and tested in the lab environment. All of the objectives were successfully achieved. This research presented the design and fabrication process of a three-level universal electric vehicle charger. The proposed charger is able to provide a controllable and constant charging voltage for various EVs and is composed of three levels of charging: (1) 650 V/100 A DC for a bus or lorry, (2) three-phase $240 \mathrm{~V} / 60 \mathrm{~A} \mathrm{AC}$ for a saloon car, and (3) single-phase $120 \mathrm{~V} / 16 \mathrm{~A}$ AC for a motorcycle. The three-phase PMW converter, based on the VOC of conversion theory and appropriate for Level 1, Level 2 and Level 3 of charging, was proposed. A new control algorithm based on the integration of the VOC and SPWM techniques for the effective operation of three battery charging level circuits was presented. A study was conducted that investigated the use of a three-phase converter unidirectional EV battery charger to be used in charging stations. It must be emphasized that a three-phase charger is employed for a full-bridge-based pulse-width modulation (PWM) rectifier (AC-DC) for the duration of charging. In the proposed design, the reactive and unstable active currents can be counteracted by the PWM rectifier via an inner current controller, $i_{q}=0$, input and output filters, and power factor correction (PFC). It is clear that the control algorithm accurately regulates the output DC voltage. At the same time, it ensures a sinusoidal input current with minimum switching ripples and distortions. The power factor of the system is almost unity, and the total harmonic distortion (THD) for the input current is less than $0.39 \%$. However, due to limitations in terms of available facilities and resources, the ability of the proposed charging strategy in performing Level 1 and Level 2 charging have not been practically verified in this work, in which only the simulation findings have presented for this aspect. Hence, for future work, the experimental validation of Level 1 and Level 2 charging will be conducted to further support the simulation findings obtained in this work and the feasibility of the proposed charging strategy. 
Author Contributions: A.S.A.-O. was mainly responsible for the simulation and experimental work, as well as the preparation of the initial draft of the manuscript. Y.H. assisted with the simulation and experimental work. R.V., A.R., and I.B.A. contributed by verifying the simulation and experimental work. M.M., N.A.R., A.A., and A.N.A.-M. contributed by revising and finalizing the manuscript.

Funding: This research was funded by Universiti Putra Malaysia (UPM) (Grant number: RUGS 05-02-12-1881RU; Grant title: Sustainable Networked Charging Station for Electric and Hybrid Vehicles). Meanwhile, the APC was funded by UNITEN BOLD publication fund.

Conflicts of Interest: The authors declare no potential conflict of interest.

\section{References}

1. Clemente, C.; Ottorino, V. Experimental study of a DC charging station for full electric and plug in hybrid vehicles. Appl. Energy 2015, 153, 131-142.

2. Fox, G.H. Getting ready for electric vehicle charging stations. In Proceedings of the IEEE Industry Applications Society Annual Meeting (IAS), Orlando, FL, USA, 9-13 October 2011.

3. Kawamura, N.; Muta, M. Development of solar charging system for plug-in hybrid electric vehicles and electric vehicles. In Proceedings of the International Conference Renewable Energy Research and Applications (ICRERA), Nagasaki, Japan, 11-14 November 2012.

4. Arancibia, A.; Strunz, K. Modeling of an electric vehicle charging station for fast DC charging. In Proceedings of the IEEE International Electric Vehicle Conference (IEVC), Greenville, SC, USA, 4-8 March 2012.

5. Reed, G.F.; Grainger, B.M.; Sparacino, A.R.; Kerestes, R.J.; Korytowski, M.J. Advancements in medium voltage DC architecture development with applications for powering electric vehicle charging stations. In Proceedings of the IEEE Energytech, Cleveland, OH, USA, 29-31 May 2012.

6. Wei, Z.; Zhao, J.; Ji, D.; Tseng, K.J. A multi-timescale estimator for battery state of charge and capacity dual estimation based on an online identified model. Appl. Energy 2017, 204, 1264-1274. [CrossRef]

7. Masoum, M.A.S.; Deilami, S.; Islam, S. Mitigation of harmonics in smart grids with high penetration of plug-in electric vehicles. In Proceedings of the IEEE Power and Energy Society General Meeting, Providence, RI, USA, 25-29 July 2010.

8. Bentley, E.C.; Suwanapingkarl, P.; Weerasinghe, S.; Jiang, T.; Putrus, G.A.; Johnston, D. The interactive effects of multiple EV chargers within a distribution network. In Proceedings of the IEEE Vehicle Power and Propulsion Conference (VPPC), Lille, France, 1-3 September 2010.

9. The Massachusetts Department of Energy Resources. Installation Guide for Electric Vehicle Supply Equipment; Massachusetts Division of Energy Resources: Boston, MA, USA, 2014; pp. 1-26.

10. National Renewable Energy Laboratory (NREL). Plug-In Electric Vehicle Hand Book for Public Charging Station Hosts; U.S Department of Energy: Washington, DC, USA, 2013; pp. 1-20.

11. Braunl, T. EV Charging Standards; University of Western Australia: Perth, Australia, 2012; pp. 1-5.

12. Metha, S. Electric plug-in vehicle/electric vehicle status report. Electr. Eng. 2010, 1-15.

13. Zhang, Y.; Qu, C. Model Predictive Direct Power Control of PWM Rectifiers under Unbalanced Network Conditions. IEEE Trans. Ind. Electron. 2015, 62, 4011-4022. [CrossRef]

14. Callaway, D.; Hiskens, I. Achieving controllability of electric loads. Proc. IEEE 2011, 99, 184-199. [CrossRef]

15. Callaway, D. Tapping the energy storage potential in electric loads to deliver load following and regulation, with application to wind energy. Energy Convers. Manag. 2009, 50, 1389-1400. [CrossRef]

16. Rodriguez, J.; Pontt, J.; Silva, C.; Correa, P.; Lezana, P.; Cortes, P.; Ammann, U. Predictive current control of a voltage source inverter. IEEE Trans. Ind. Electron. 2007, 54, 495-503. [CrossRef]

17. Rivera, M.; Yaramasu, V.; Rodriguez, J.; Wu, B. Model predictive current control of two-level four-leg inverters-Part II: Experimental implementation and validation. IEEE Trans. Power Electron. 2013, 28, 3469-3478. [CrossRef]

18. Young, H.A.; Perez, M.A.; Rodriguez, J.; Abu-Rub, H. Assessing finite-control-set model predictive control: A comparison with a linear current controller in two-level voltage source inverters. IEEE Ind. Electron. Mag. 2014, 8, 44-52. [CrossRef]

19. Yaramasu, V.; Rivera, M.; Narimani, M.; Wu, B.; Rodriguez, J. Model predictive approach for a simple and effective load voltage control of four-leg inverter with an output LC filter. IEEE Trans. Ind. Electron. 2014, 61, 5259-5270. [CrossRef] 
20. Chen, Q.; Luo, X.; Zhang, L.; Quan, S. Model predictive control for three-phase four-leg grid-tied inverters. IEEE Access 2017, 5, 2834-2841. [CrossRef]

21. Jackson, D.; Schultz, A.; Leeb, S.B.; Mitwalli, A.; Verghese, G.; Shaw, S.R. A multirate digital controller for a 1.5-kW electric vehicle battery charger. IEEE Trans. Power Electron. 1997, 12, 1000-1006. [CrossRef]

22. Kisacikoglu, M.C.; Kesler, M.; Tolbert, L.M. Single-phase on-board bidirectional PEV charger for V2G reactive power operation. IEEE Trans. Smart Grid 2015, 6, 767-775. [CrossRef]

23. Fasugba, M.A.; Krein, P.T. Gaining vehicle-to-grid benefits with unidirectional electric and plug-in hybrid vehicle chargers. In Proceedings of the IEEE Vehicle Power and Propulsion Conference, Chicago, IL, USA, 6-9 September 2011.

24. Al-Ogaili, A.S.; Aris, I.; Othman, M.L.; Hoon, Y.; Isa, D.; Azis, N.; Abbas, H.F. A review of Different Control Methods in Power Electronics. J. Eng. Appl. Sci. 2018, 13, 2242-2253.

25. Ottersten, R. On Control of Back-to-Back Converters and Sensorless Induction Machine Drives; Department of Electric Power Engineering, Chalmers University of Technology: Goteborg, Sweden, 2003.

26. Zainuri, M.A.A.M.; Radzi, M.A.M.; Soh, A.C.; Mariun, N.; Rahim, N.A. Dc-link capacitor voltage control for single-phase shunt active power filter with step size error cancellation in self-charging algorithm. IET Power Electron. 2016, 9, 323-335. [CrossRef]

27. Hoon, Y.; Radzi, M.A.M.; Hassan, M.K.; Mailah, N.F. DC-Link Capacitor Voltage Regulation for Three-Phase Three-Level Inverter-Based Shunt Active Power Filter with Inverted Error Deviation Control. Energies 2016, 9, 533. [CrossRef]

(C) 2019 by the authors. Licensee MDPI, Basel, Switzerland. This article is an open access article distributed under the terms and conditions of the Creative Commons Attribution (CC BY) license (http://creativecommons.org/licenses/by/4.0/). 